\title{
Control of Photoinduced Energy- and Electron-Transfer Steps in Zinc Porphyrin-Oligothiophene-Fullerene Linked Triads with Solvent Polarity
}

Takumi Nakamura, ${ }^{\dagger}$ Jun-ya Ikemoto, ${ }^{\ddagger}$ Mamoru Fujitsuka, ${ }^{\dagger, \not l}$ Yasuyuki Araki, Osamu Ito, ${ }^{*, \dagger}$ Kazuo Takimiya, ${ }^{\ddagger}$ Yoshio Aso, ${ }^{\ddagger}, \mathbb{I}$ and Tetsuo Otsubo ${ }^{\ddagger} * *$

Institute of Multidisciplinary Research for Advanced Materials, Tohoku University, Katahira, Sendai, Miyagi 980-8577, Japan and Department of Applied Chemistry, Graduate School of Engineering, Hiroshima University, Higashi-Hiroshima 739-8527, Japan

To whom correspondence should be addressed.

E-mail: ito@tagen.tohoku.ac.jp, otsubo@hiroshima-u.ac.jp

${ }^{\dagger}$ Tohoku University.

${ }^{\ddagger}$ Hiroshima University.

IPresent address: The Institute of Scientific and Industrial Research, Osaka University, Ibaraki, Osaka 567-0047, Japan. 
Optimized Structures and Molecular Orbitals. To obtain insights into the optimized structures and molecular orbitals of $\mathrm{ZnP}-n \mathrm{~T}-\mathrm{C}_{60}$, computational studies were performed using density functional method (DFT) at the B3LYP/3-21G(*) level. [reference 26 in text] Figures 2 and 3 show the optimized structures of $\mathrm{ZnP}-4 \mathrm{~T}-\mathrm{C}_{60}$ and $\mathrm{ZnP}-8 \mathrm{~T}-\mathrm{C}_{60}$, respectively. The geometrical parameters were evaluated from the optimized structures as listed in the captions of Figure 2 and 3. For both ZnP-4T$\mathrm{C}_{60}$ and $\mathrm{ZnP}-8 \mathrm{~T}-\mathrm{C}_{60}$, the HOMO localizes on the $\mathrm{ZnP}$ moiety, while the LUMO lies on the $\mathrm{C}_{60}$ moiety. The energies and MO shapes of the lower HOMO (HOMO-1) are almost the same as those of HOMO, suggesting both MOs are nearly degenerated. The second lower HOMO (HOMO-2) is on the $n \mathrm{~T}$ moiety. These findings indicate that the $\pi$-conjugation of the $n \mathrm{~T}$ moiety does not extend to the $\mathrm{ZnP}$ moiety; therefore, the $n \mathrm{~T}$ and $\mathrm{ZnP}$ moieties act as electron donors independently. In general, the relative energies of the CS states may vary with the solvent properties, because these MO calculations were performed without considering interaction with solvent. 
(a)

(b)

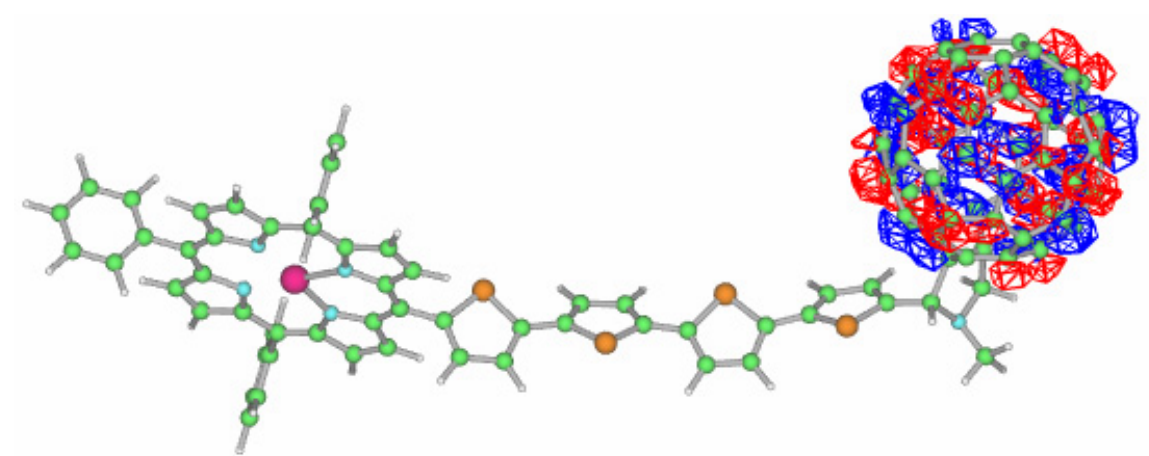

\section{LUMO}

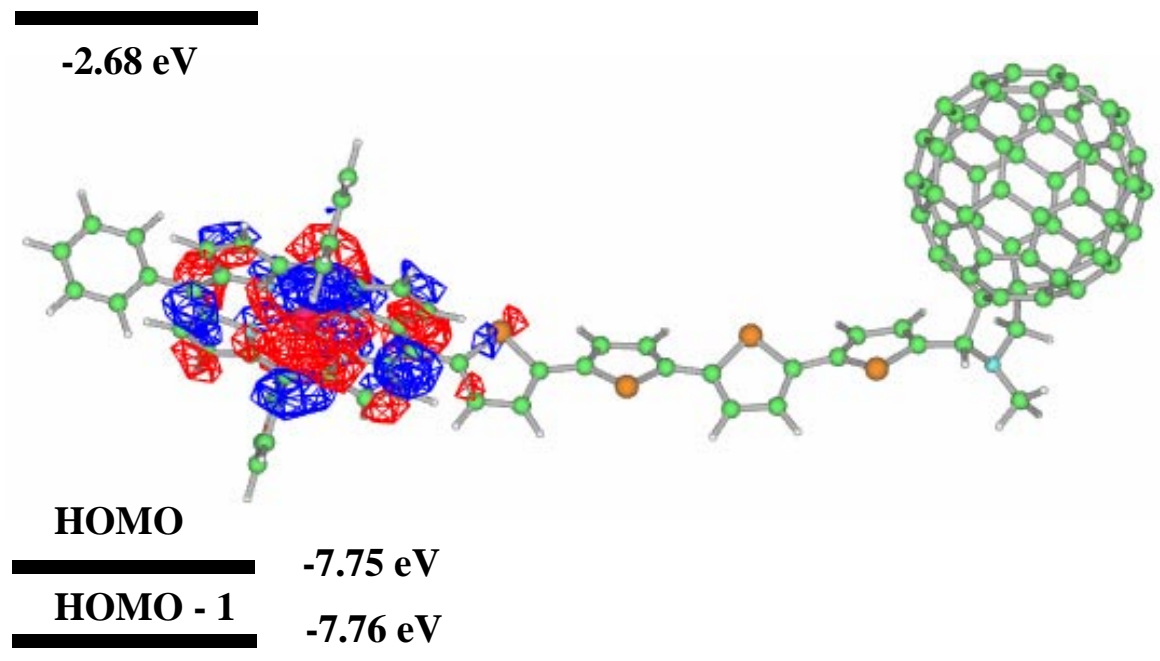

(c)

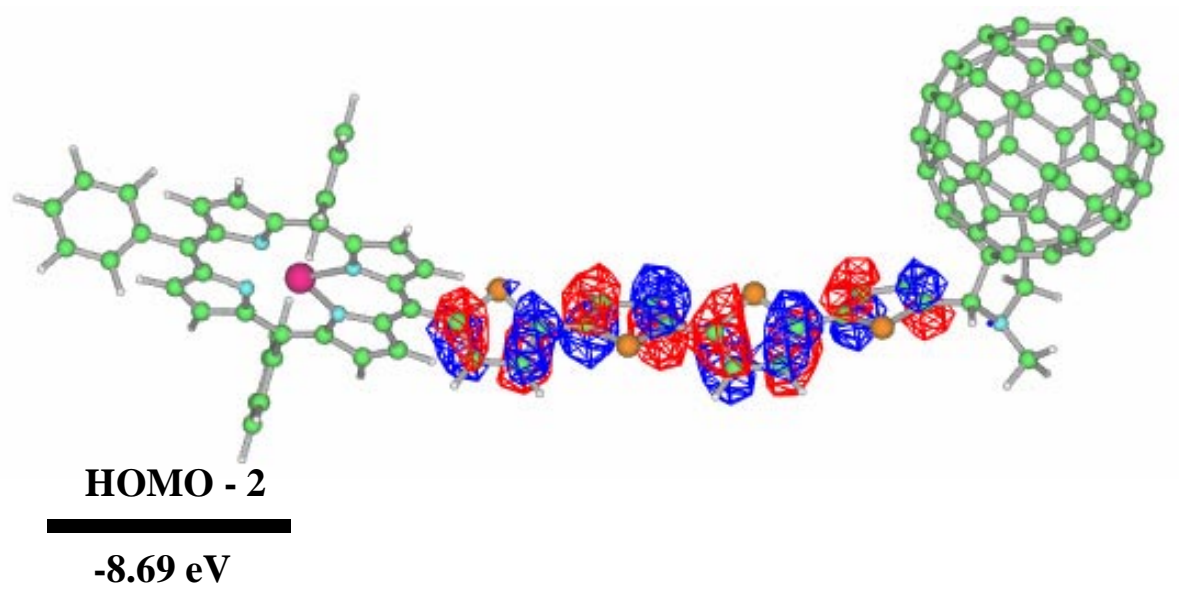

Figure S1. (a) LUMO, (b) HOMO, HOMO-1, and (c) HOMO-2 of $\mathrm{ZnP}-4 \mathrm{~T}-\mathrm{C}_{60}$ triad; $R_{\mathrm{P}-\mathrm{C}}=25.3$

$\AA, R_{4 \mathrm{~T}-\mathrm{C}}=12.8 \AA, R_{\mathrm{P}}=5.0 \AA, R_{4 \mathrm{~T}}=7.5 \AA$ and $R_{\mathrm{C}}=4.2 \AA$. 
(a)

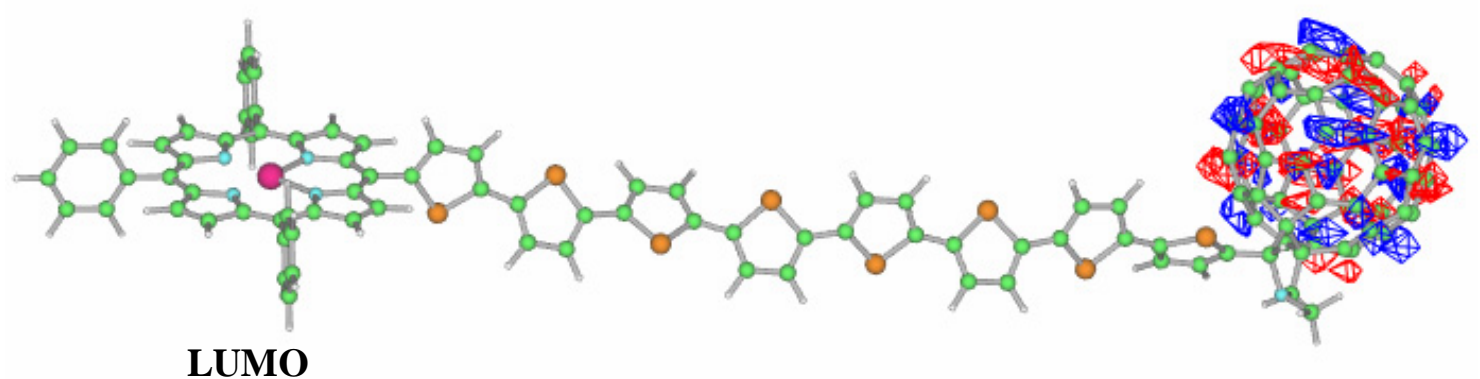

\section{$-2.68 \mathrm{eV}$}

(b)
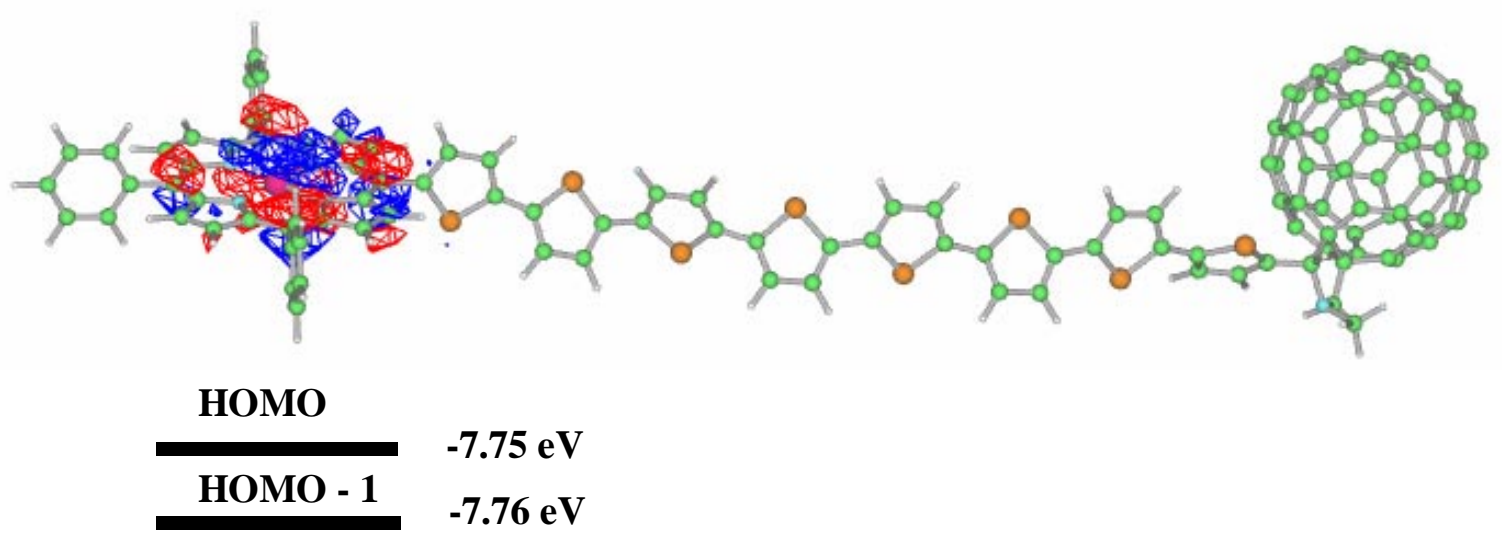

(c)

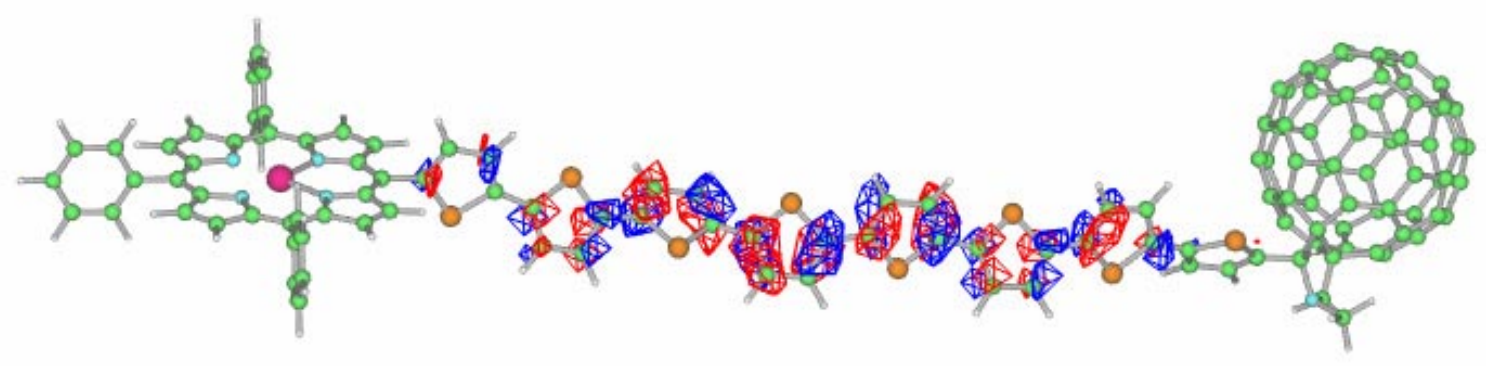

HOMO - 2

$-8.48 \mathrm{eV}$

Figure S2. (a) LUMO, (b) HOMO, HOMO-1 and (c) HOMO-2 of the $\mathrm{ZnP}-8 \mathrm{~T}-\mathrm{C}_{60}$ triad; $R_{\mathrm{P}-\mathrm{C}}=$ $40.5 \AA, R_{8 \mathrm{~T}-\mathrm{C}}=20.4 \AA, R_{\mathrm{P}}=5.0 \AA, R_{8 \mathrm{~T}}=14.5 \AA$ and $R_{\mathrm{C}}=4.2 \AA$. 


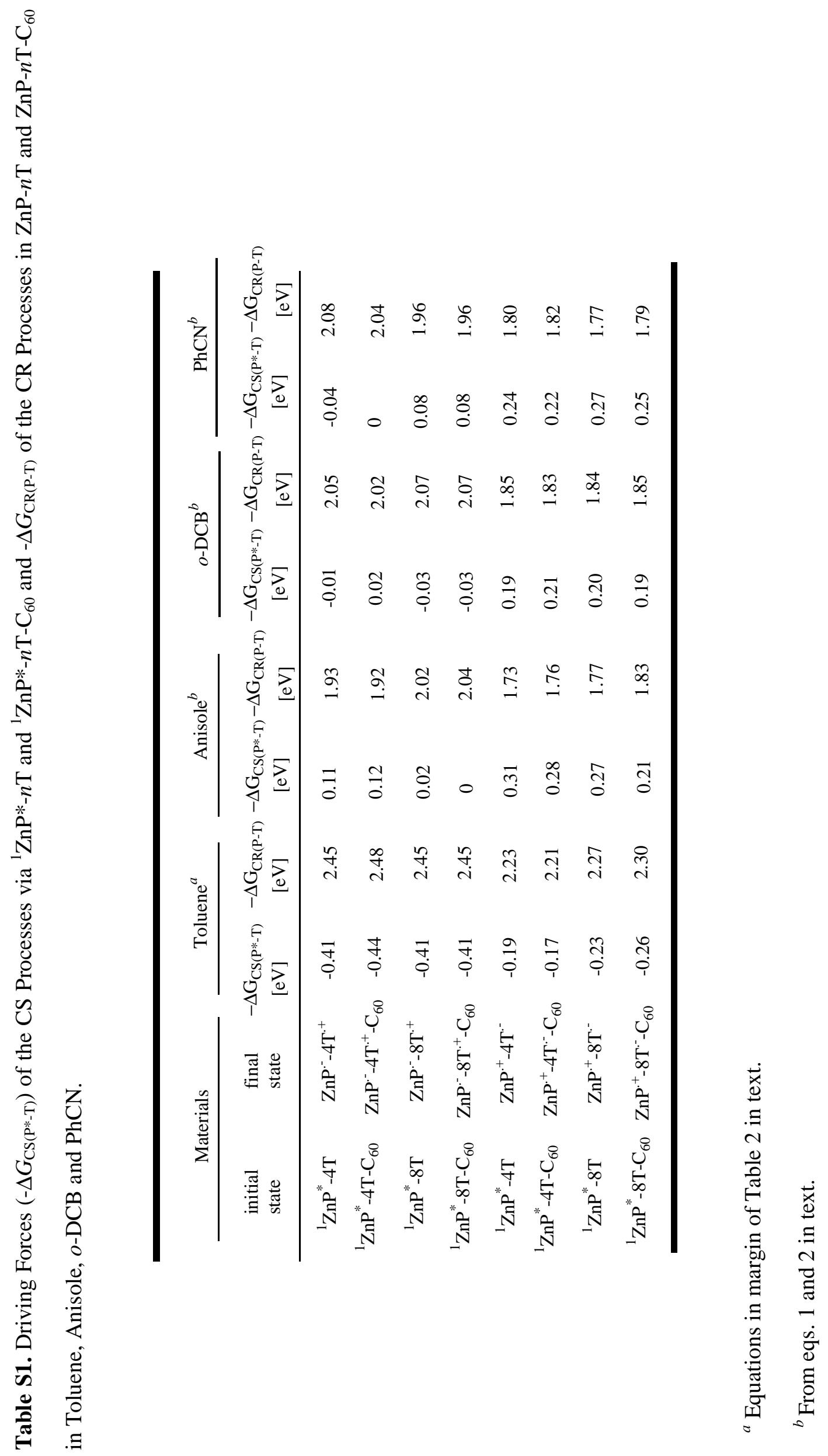




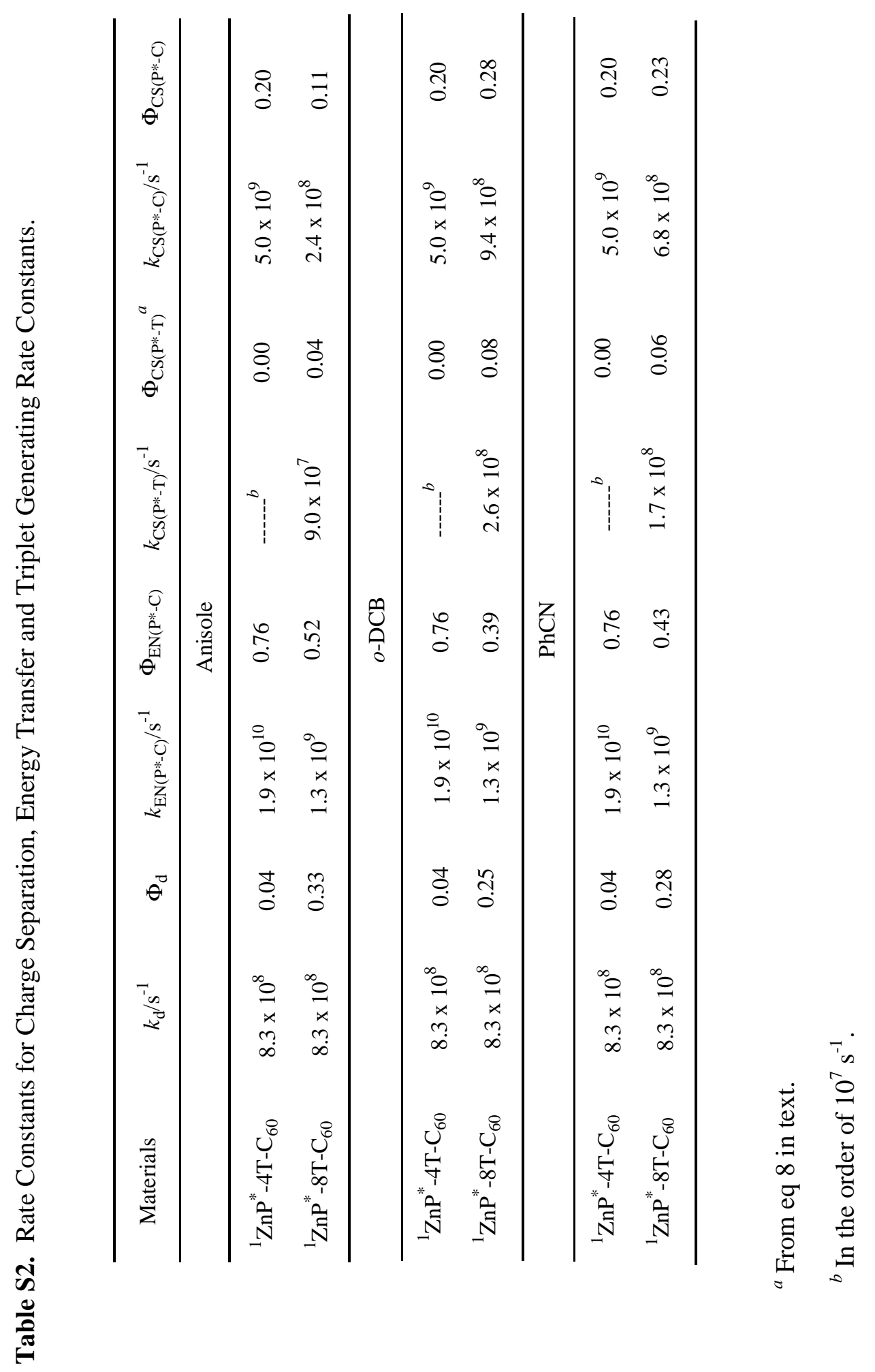




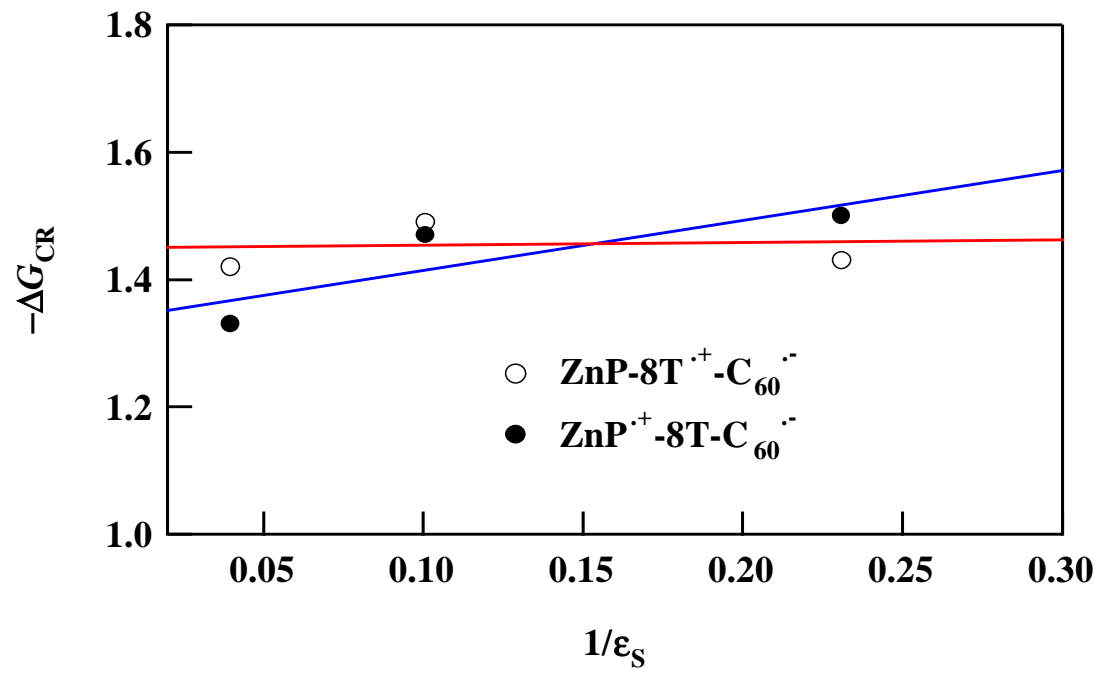

Figure S3. Solvent polarity dependence of the free energy changes $\left(-\Delta G_{\mathrm{CR}}\right)$ for the CS states between the $\mathrm{ZnP}$ and $\mathrm{C}_{60}$ moieties $(\bullet)$, and the $8 \mathrm{~T}$ and $\mathrm{C}_{60}$ moieties (०).

Figure $\mathrm{S} 3$ gave the linear relations $-\Delta G_{\mathrm{CR}}=\mathrm{A}+\mathrm{B}\left(1 / \varepsilon_{\mathrm{S}}\right)$, where $\varepsilon_{\mathrm{S}}$ is a static dielectric constant of solvent; $\varepsilon_{\mathrm{S}}=4.33$ (anisole), $\varepsilon_{\mathrm{S}}=9.93(o-\mathrm{DCB})$ and $\varepsilon_{\mathrm{S}}=25.2(\mathrm{PhCN})$. Since B for $\mathrm{ZnP}^{\circ+}-8 \mathrm{~T}-\mathrm{C}_{60}{ }^{\circ-}$ is larger than that of $\mathrm{ZnP}-8 \mathrm{~T}^{\circ+}-\mathrm{C}_{60}{ }^{\circ-}$, the values of $-\Delta \mathrm{G}_{\mathrm{CR}}$ for $\mathrm{ZnP}^{\bullet+}-8 \mathrm{~T}-\mathrm{C}_{60}{ }^{--}$change more drastic than those of $\mathrm{ZnP}_{-} 8 \mathrm{~T}^{\bullet+}-\mathrm{C}_{60}{ }^{\bullet-}$; i.e. energy level of $\mathrm{ZnP}^{\bullet+}-8 \mathrm{~T}-\mathrm{C}_{60}{ }^{\bullet-}$ becomes higher than that of $\mathrm{ZnP}-8 \mathrm{~T}^{\circ+}-\mathrm{C}_{60}{ }^{-{ }^{-}}$ in less polar solvents, while opposite in polar solvents, and in $o$-DCB, the both energy levels are almost the same. 
Table S3. Free Energy Changes $\left(\Delta G_{\mathrm{CR}}\right)$, Rate Constants $\left(k_{\mathrm{CR}}\right)$ for Charge Recombination and Lifetimes of Radical Ion-Pair ( $\left.\tau_{\mathrm{RIP}}\right)$ in Anisole observed by Transient Absorption Measurements

\begin{tabular}{ccccc}
\hline initial state & final state & $-\Delta G_{\mathrm{CR}} / \mathrm{eV}$ & $k_{\mathrm{CR}} / \mathrm{s}^{-1}$ & $\tau_{\mathrm{RIP}}$ \\
\hline $\mathrm{H}_{2} \mathrm{P}-4 \mathrm{~T}^{+}{ }^{+} \mathrm{C}_{60}{ }^{--}$ & $\mathrm{H}_{2} \mathrm{P}-4 \mathrm{~T}-\mathrm{C}_{60}$ & 1.72 & $1.9 \times 10^{5}$ & $5.3 \mu \mathrm{s}$ \\
$\mathrm{H}_{2} \mathrm{P}-8 \mathrm{~T}^{+}{ }^{+} \mathrm{C}_{60}{ }^{--}$ & $\mathrm{H}_{2} \mathrm{P}-8 \mathrm{~T}-\mathrm{C}_{60}$ & 1.61 & $2.2 \times 10^{5}$ & $4.5 \mu \mathrm{s}$ \\
\hline
\end{tabular}




\section{For the energy transfer (Figure S4).}

According to the Förster theory, ${ }^{\text {[reference } 28 \text { in text] }}$ the energy-transfer rate constant, $k_{\mathrm{EN}}($ theory), can be estimated using eq $\mathrm{S} 1$.

$$
\left.k_{\mathrm{EN}}(\text { theory })=8.79 \times 10^{-25}\left(k_{\mathrm{D}} \kappa^{2} J / n^{4} R_{\mathrm{DA}(\mathrm{P}-\mathrm{C})}\right)^{6}\right)
$$

Hereby, $k_{\mathrm{D}}$ is refereed to the radiative rate constant which is calculated from fluorescence quantum yield and the fluorescence lifetime of the dyad. The $n$ is the reflective index of solvent and $\kappa$ is the orientation factor. The spectral overlap integrations $\left(J=6.0 \times 10^{-20}\right.$ and $6.2 \times 10^{-20} \mathrm{M}^{-1} \mathrm{~cm}^{3}$ for ZnP-4T$\mathrm{C}_{60}$ and ZnP-8T- $\mathrm{C}_{60}$, respectively) are estimated from the absorption spectrum of acceptor $(\varepsilon(\lambda))$ and the normalized emission spectrum of donor $(F(\lambda))$ as eq S2 (Figure S4).

$$
J=\int \varepsilon(\lambda) F(\lambda) \lambda^{4} \mathrm{~d} \lambda
$$

The $k_{\mathrm{EN}}$ (theory) values were estimated to be $8.8 \times 10^{9}$ and $9.1 \times 10^{8}$ for $\mathrm{ZnP}-4 \mathrm{~T}-\mathrm{C}_{60}$ and ZnP-8T-C 60 , respectively. These values are in good agreement with the $k_{\mathrm{EN}\left(\mathrm{P} *_{-} \mathrm{C}\right)}$ values evaluated experimentally, which indicates that the energy transfer obeys the Förster mechanism. The Förster radii were evaluated based on the model compounds as half distance between the ZnP moiety and the $\mathrm{C}_{60}$ moiety $(12.8 \AA$ and $20.2 \AA$ for $\mathrm{ZnP}-4 \mathrm{~T}-\mathrm{C}_{60}$ and $\mathrm{ZnP}-8 \mathrm{~T}-\mathrm{C}_{60}$, respectively).

This energy transfer is a reasonable process even in polar solvents, although the quantum yields drastically decrease with $\left.R_{\mathrm{DA}(\mathrm{P}-\mathrm{C})}\right)$. 


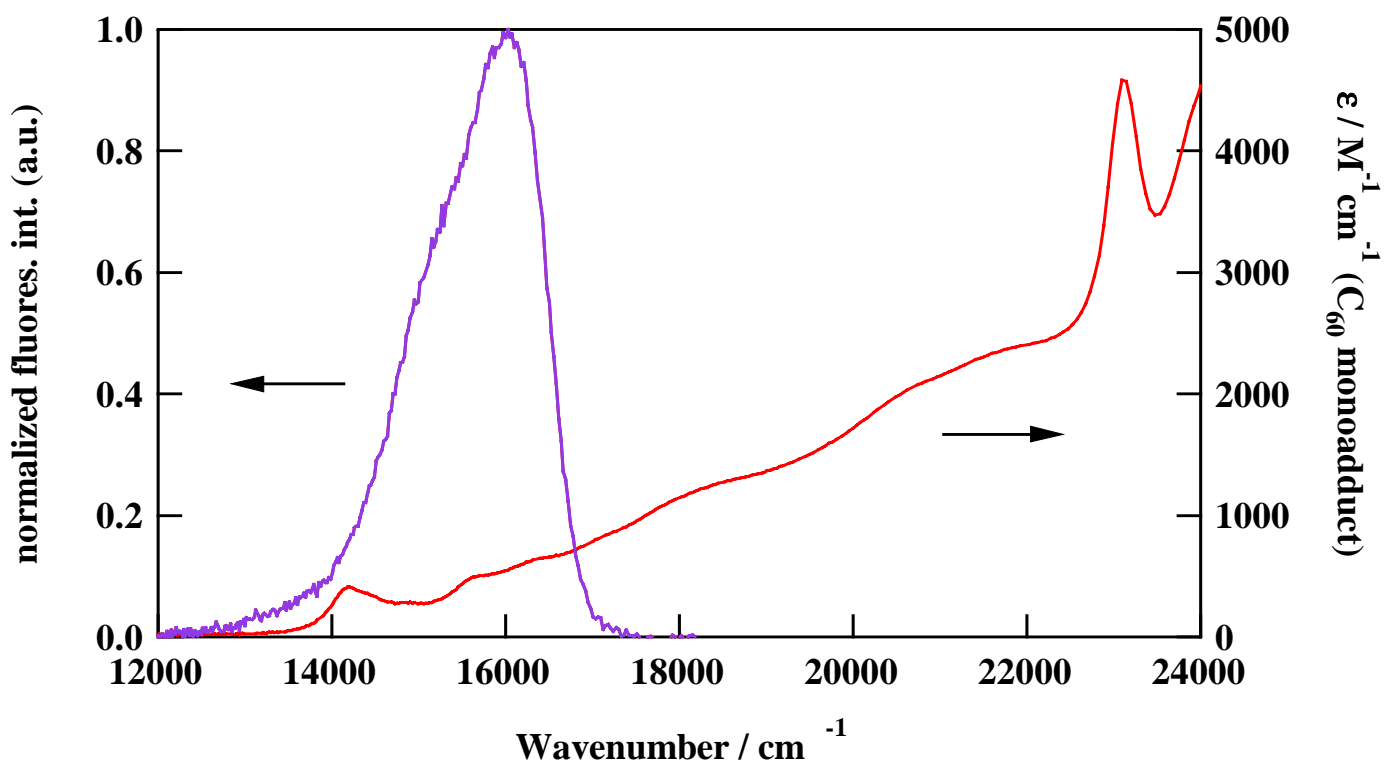

Figure S4. Steady-state adsorption spectrum of $\mathrm{C}_{60}$ and fluorescence spectrum of the ${ }^{1} \mathrm{ZnP} *$ moiety in ZnP-4T dyad in toluene. The ZnP moiety was excited by 420-nm light. 